Rev. Saude puibl., S. Paulo

$8: 447-50,1974$

\title{
NOTA SOBRE A DIFERENCIAÇÃO DE OVOS DE RHODNIUS NEGLECTUS E R. PROLIXUS *
}

Oswaldo Paulo FORATTINI**

José Maria Soares BARATA**

RSPU-B/239

Forattini, O. P. \& Barata, J. M. S. - Nota sobre a diferenciação de ovos de Rhodnius neglectus e R. prolixus. Rev. Saúde públ., S. Paulo, 8:447$-50,1974$.

RESUMO: Descreve-se característica morfologica diferencial que permite distinguir os ovos de Rhodnius neglectus $e$ R. prolixus. Trata-se de formação saliente ao redor da região pré-opercular disposta à maneira de "colarinho", existente na primeira e ausente na segunda dessas espécies.

UNITERMos: Rhodnius neglectus*; Rhodnius prolixus*; Doença de Chagas *; Rhodnius (diversas espécies).

0 encontro mais recente de ${ }^{\circ}$ hodnius prolixus no Estado de São Paulo, Brasil, levantou novamente o problema da identificação dessa espécie e de sua diferenciação de $R$. neglectus, com a qual foi anteriormente confundida (Tavares ${ }^{4}$, 1972). E é compreensível que esse problema mereça atenção, uma vez que se trata de triatomíneo altamente significativo para a transmissão da doença de Chagas.

Com efeito, é conhecida a ocorrência de Rhodnius prolixus em ambiente extradomiciliar, principalmente na Venezuela (GAMBOA $\left.{ }^{2}, 1965\right)$. Em tais situações, o inseto fui encontrado ocupando ecótopos em todo semelhantes àqueles que, na re- gião meridional do Brasil, foram observados para $R$. neglectus, ou seja, em palmeiras. Por conseguinte, a possivel coexistência das duas espécies na mesma área, faz surgir a questão do seu reconhecimento mais acurado.

E sabido que não é fácil a diferenciação específica desses dois triatomíneos. Freqüentemente, os serviços encarregados do controle da tripanossomíase americana tem esbarrado com dificuldades no diagnóstico rotineiro. As formas adultas são muito semelhantes, o que obriga a estudos de morfologia de genitália para alcançar identificação satisfatória. Daí pois a utilidade em evidenciar caracteres que sejam mais acessíveis à observação.

* Trabalho do Departamento de Epidemiologia da Faculdade de Saúde Pública da Universidade de São Paulo, levado a efeito com o auxillo do Conselho Nacional de Pesquisas (Proc. CNPq n.o 10807)

* Do Departamento de Epidemiologia da Faculdade de Saúde Pública da USP - Av. Dr. Arnaldo, 715 - São Paulo, SP - Brasil 
FORATTINI, O.P. \& BARATA, J.M.S. - Nota sobre a diferenciaçāo de ovos d eRhodnius neglectus e $R$. prolixus. Rev. Saúde puibl., S. Paulo, 8:447-50, 1974.

No presente trabalho mostra-se a existência de diferença simples, entre essas duas espécies. tomando por base a arquitetura dos ovos. Embora, à primeira vista. possa não parecer fácil a obtenção dessas formas, na verdade o seu encontro é mais freqüente do que se possa imaginar. $\mathrm{Na}$ pesquisa de triatomíneos, particularmente nas áreas cujo programa se encontra em fase de vigilância. os serviços encarregados têm encontrado, com maior frequiência, apenas ovos ou cascas vazias. Por outro lado, ao se desejar diagnóstico de confirmação, e desde que se tenham coletado apenas fêmeas, bastará aguardar a oviposição, uma vez que, devido à elevada prolixidade desses insetos e à relativa resistência às mudanças de meio ambiente, não é difícil a obtenção de tais elementos.

Com esse objetivo, foram examinados ovos e respectivas cascas, de Rhodnius neglectus e $R$. prolixus, de todas as colônias mantidas no insetário do Departamento de Epidemiologia da Faculdade de Saúde Pública da USP e cujas procedências são as seguintes: $R$. neglectus - RCT - 20 Pitangueiras, São Paulo. Brasil; RCT - 23 Guaira. São Paulo. Brasil; RCT - 48 Monte Alto, São Paulo, Brasil; RCT - 68 Sales de Oliveira, São Paulo. Brasil; RCT - 121 Insetário Dr. Zeleidon. El Salvador, Costa Rica; R. prolixus - RCT - 5 Insetário Faculdade de Medicina da USP, São Paulo, Brasil; RCT - 45 Insetário da Lniversidade de ValleCali, Colômbia; RCT - 123 Insetário do Laboratório Com. Gorgas, El Salvador, Costa Rica; RCT - 145 Insetário Dr. Torrealba, Caracas, Venezuela.

Para as macrofotografias foram usados ovos férteis. Para as microfotografias, utilizaram-se as cascas, previamente tratadas segundo técnica de LuCENA ${ }^{3}$ (1969), ou seja, amolecimento por 12 a 24 horas em solução de álcool $90^{\circ}(90 \mathrm{ml})$, glicerina $(10 \mathrm{ml})$ e fenol $(1 \mathrm{ml})$. Após o que foram cortados pequenos fragmentos da área próxima ao opérculo.
Na prática, para tais observaçōes, basta a utilização de qualquer lupa estereoscópica. com luz natural ou luz artificial direta. à custa de lâmpadas comuns de 40, 60 ou 100 velas.

Foi observado assim que, no material estudado, os ovos de $R$. neglectus possuem formação bastante evidente. à maneira de anel e contornando a região logo abaixo do opérculo, a qual, pela semelhança, convencionamos chamar de "colarinho" (Fig. $1)$. Por sua vez, os vos de $R$. prolixus, de aspecto muito semelhante ao de $R$. neglectus quanto ao tamanho, textura, coloração. etc., não possuem essa formação (Fig. 2).

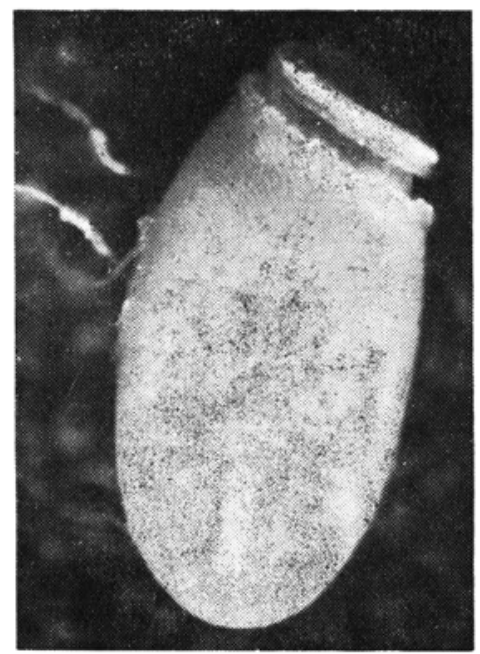

Fig. 1 - Ovos de Rhodnius neglectus notando-se o "colarinho" logo abaixo do opérculo $(12,5 \times)$.

Em fragmentos de casca de ovos dessas espécies, examinadas segundo técnica já citada, pôde-se também constatar essa diferença. Assim, em $R$. prolixus essa região é lisa (Fig. 3 ) ao passo que em $R$. neglectus existe faixa de nítidas vilosidades, contornando toda a área (Fig. 4). Embora não se tenham feito estudos histológicos, esse "colarinho" parece ser formado de aglutinação do mesmo material do exocório. E isso porque ali nota-se a 
FORATTINI, O.P. \& BARATA, J.M.S. - Nota sobre a diferenciação de ovos d eRhodnius neglectus e $R$. prolixus. Rev. Saúde públ., S. Paulo, 8:447-50, 1974.

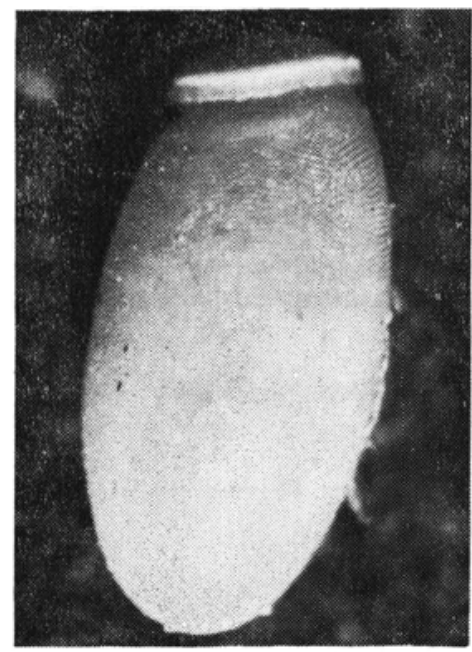

Fig. 2 - Ovos de Rhodnius prolixus $(12,5 \times)$.

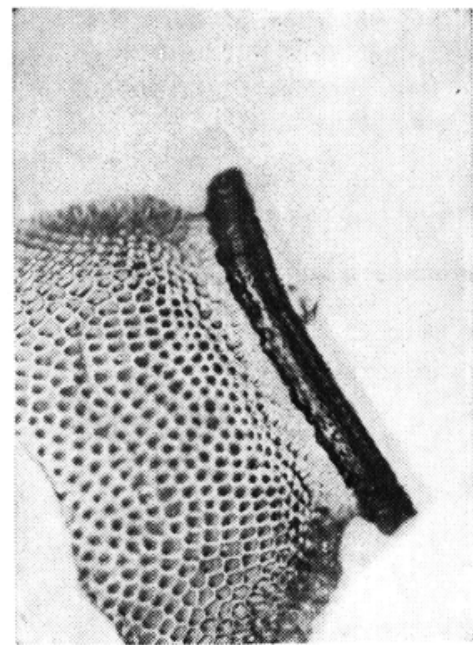

Fig. 3 - Microfotografía da região pré-opercular de ovo de Rhodnius prolixus $(80 \times)$.

presença dos pequenos "tubos na extremidade da cavidade" (BARTH \& MUTH ${ }^{1}$, 1958). Este colarinho parece não ter, pelo menos no estado atual dos conhecimentos, função de fixação, pois, no abundante material examinado, esta é sempre feita no corpo do ovo.

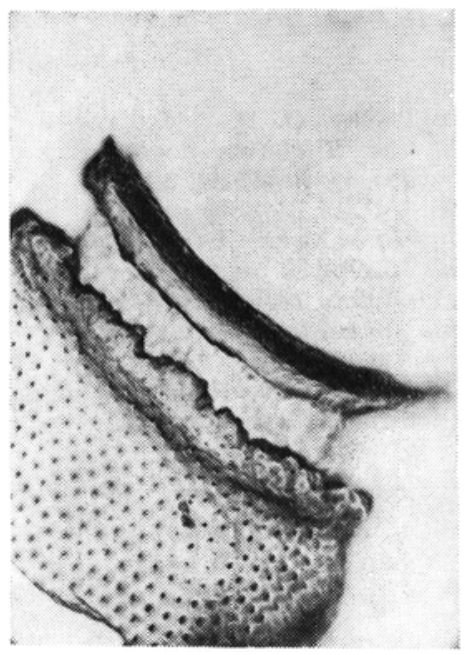

Fig. 4 - Microfotografia da região pré-opercular de ovo de Rhodnius neglectus, notando-se o "colarinho" logo abaixo da linha do opéreulo $(80 x)$.

Outras espécies de Rhodnius possuem ovos com o "colarinho". Do material que pudemos dispor, foi constatada sua presença em Rhodnius nasutus, $R$. neivai e $R$. pallescens. Nesta última, embora pouco proeminente, é bastante nítido devido à coloração escura da casca, fator esse, aliás, que torna tal espécie inconfundível perante as outras do gênero. Por outro lado, pudemos verificar que, além de $R$. prolixus, a ausência desse "colarinho" ocorre também em $R$. robustus e em $R$. domesticus. Ainda assim, a ocorrência ou não dessa formação constitui caráter diferencial importante entre $R$. neglectus \& $R$. prolixus. Para as outras espécies, no que se diz respeito particularmente aos aspectos morfológico, ecológico e de distribuição geográfica, dificilmente poderiam suscitar dúvidas quanto à sua diferenciação. Isso, entretanto, não acontece com esses dois triatomíneos que, como se referiu, além de serem morfologicamente semelhantes, apresentam a possibilidade de coexistência. 
FORATTINI, O.P. \& BARATA, J.M.S. - Nota sobre a diferenciação de ovos d eRhodnius neglectus e $R$. prolixus. Rev. Saúde públ., S. Paulo, 8:447-50, 1974.

RSPU-B/239

Forattini, O. P. \& Barata, J. M. S. - [Note on the differentiation between the Rhodnius neglectus and the R. prolixus eggs.] Rev. Saúde públ., $S$. Paulo, 8:447-50, 1974.

SUMmary: An evident structural process allowing the distinction between the Rhodnius neglectus and $\mathrm{R}$. prolixus eggs is described. The former presents a complete collar occupying the preopercular region whilst in the latter species this formation is lacking.

UNITERMS: Rhodnius neglectus*; Rhodnius prolixus*; Chagas' disease*; Rhodnius, several species.

\section{REFERENCIAS BIBLIOGRAFICAS}

1. BARTH, R. \& MUTH, H. - Estudos anatômicos e histológicos sobre a subfamilia Triatomínea (Heteroptera, Reduvidae). VIII parte: Observações sobre a superfícle dos ovos das espécies mais importantes. Mem. Inst. Oswaldo Cruz, $\mathbf{5 6 : 1 9 7 - 2 0 8 , 1 9 5 8 .}$

2. GAMBOA, C.I. - Comprobacion de Rhodnius prolixus extradoméstico em Venezuela. Arch, venez. Med. trop, , 5: 283-98, 1965.

3. LUCENA, D.T. \& MORAES REGO, A. Microestrutura do exocório de ovos de Triatomíneos do Nordeste do Brasil. Rev. Inst. Med. trop. S. Paulo, 11:87-93, 1969 .

4. TAVARES, O. - Nota sobre a presenca de Rhodnius prolixus Stal, 1859, no Estado de São Paulo, Brasil (Hemiptera, Reduvidae, Triatominae). Rev. Soc. bras. Med. trop. 5:321-3, 1972.

Recebido para publicação em 4/9/1974 Aprovado para publicação em 4/10/1974 